Article

\title{
Mechanical and Damping Properties of Recycled Aggregate Concrete Modified with Air-Entraining Agent and Polypropylene Fiber
}

\author{
Chonggang Zhou, Xingwang Pei *, Wenlong Li and Yijun Liu \\ College of Civil Engineering, Xi'an University of Architecture \& Technology, Xi'an 710055, China; \\ wisdom181@126.com (C.Z.); li1536295967@126.com (W.L.); appleliuyijun@sina.com (Y.L.) \\ * Correspondence: peixingwang@xauat.edu.cn; Tel.: +86-1872-908-1868
}

Received: 28 February 2020; Accepted: 21 April 2020; Published: 24 April 2020

check for updates

\begin{abstract}
In this study, recycled aggregate concrete (RAC) modified with polypropylene fiber (PP) and air-entraining agent (AGA) was prepared, and the effects of PP and AGA on the static (compressive strength, Young's modulus, and splitting tensile strength) and dynamic properties (dynamic modulus of elasticity and damping ratio) of RAC were investigated. The experimental results showed that the addition of an AGA and PP had a favorable effect on the damping ratio of the concrete, however, the addition of the AGA had a slightly negative effect on the mechanical performance of the concrete. The AGA and PP contents required to achieve the optimum damping ratio of the concrete with the least reduction in the mechanical performance were $0.02 \%$ and $0.10 \%$, respectively. Furthermore, the addition of AGA was more effective than that of PP in improving the damping property of the concrete.
\end{abstract}

Keywords: recycled aggregate concrete; interface transition zone; static properties; dynamic behavior; damping mechanism; air-entraining agent

\section{Introduction}

Concrete is the most common construction material and has been extensively used in buildings, bridges, and dams owing to the advantages of its low cost, abundant raw materials, high strength, and excellent durability [1,2]. Aggregate accounts for approximately $60-70 \%$ of all raw materials in the concrete production [3-6]. However, concrete consumption is expected to increase with the continuous growth of the infrastructure industry $[7,8]$. Consequently, non-renewable aggregate resources may get exhausted [4]. Therefore, an alternative material to replace natural aggregate and to relieve the current pressure on the sustainable development of environment is urgently needed [4,9].

Recycled concrete aggregate (RCA) is manufactured from abandoned concrete blocks by a series of processes, including washing, crushing, and grading. RCA is a renewable resource and can be used to alleviate environment pollution $[10,11]$. Studies have indicated that the partial replacement of natural concrete aggregate (NCA) with RCA to prepare recycled aggregate concrete (RAC) has immense potential for practical applications [12]. RAC is composed of the original aggregate, an adhered old cement mortar, and two types of interface transition zones (ITZs) [4]. However, it exhibits weaker mechanical properties and lower durability than NCA due to the inferior properties of its constituents $[4,12]$.

Dynamic characteristics govern the intrinsic properties of a material and can reflect the behavior of a material under dynamic loading [13]. Such characteristics facilitate the dispersion and conversion of energy during the vibration process $[7,14]$. Further, they can help in improving the stability and safety of the concrete structure. There are three types of damping in concrete [7]: system damping, 
structural damping, and material damping. System and structural damping are external damping (viscous damping, dry damping, hysteresis damping, nonlinear damping, etc.) [15,16], and material damping is internal damping (medium damping, friction damping, etc.) [17]. The damping ratio is the dominant property that indicates the dynamic characteristics of a material [18-20]. Therefore, it has been widely used for the dynamic analysis of building structures [4,7-10]. To date, several studies have focused on the damping of RAC [11], while some have mainly focused on the effect of the replacement ratio and size of RCA on the damping performance of RAC [4,7].

Studies have suggested that due to its high tensile strain, a fiber polymer, as an additive, can contribute to improving the performance of concrete $[3,7,21,22]$. Furthermore, the study of the effect of the type and dosage of fiber on the mechanical properties of RAC has shown that concrete reinforced with glass and steel fibers can significantly improve the mechanical performance of RAC when the fiber content is within a reasonable range [23]. Additionally, the air entraining agent (AGA) introduces many bubbles in concrete, and it may increase the damping performance of the concrete to a certain extent. Few studies have investigated the properties of RAC modified with polypropylene fiber (PP) and AGA. Specifically, the damping properties of pure concrete and concrete modified with AGA and PP have rarely been compared.

In this study, for the first time, RAC was incorporated with the advantage of PP as well as the high damping characteristic of AGA. The damping properties of RAC at various PP and AGA contents were compared with those of the reference concrete. Our results provide a deep understanding of the dynamic behavior of RAC modified with PP and AGA and potentially serve as an effective tool for designing concrete with excellent damping property.

\section{Materials and Methods}

\subsection{Raw Materials}

\subsubsection{Cementitious Materials}

The cementitious materials used were ordinary Portland cement (P.O 42.5) and fly ash (FA). The cement was purchased from Shaanxi Qinling Cement Co., Ltd. (Yaoxian, Shaanxi, China), and the FA was purchased from Shenmu County Huatai Clean Coal Technology Development Co., Ltd. (Shenmu, Shaanxi, China). Table 1 presents the chemical composition and physical properties of cement according to Chinese Standard GB 175-2007 [24]. Table 2 shows the chemical composition of FA, which complies with the requirements of the Chinese Standard GB/T 51003-2014 [25]. Figures 1 and 2 show the scanning electron micrograph and particle size distribution of FA, respectively.

Table 1. Chemical composition and physical properties of the cement.

\begin{tabular}{ccccccccccc}
\hline \multicolumn{4}{c}{ Chemical Composition (wt.\%) } & \multicolumn{3}{c}{ Primary Physical Properties } \\
\hline $\mathrm{CaO}$ & $\mathrm{SiO}_{2}$ & $\mathrm{Al}_{2} \mathrm{O}_{3}$ & $\mathrm{Fe}_{2} \mathrm{O}_{3}$ & $\mathrm{SO}_{3}$ & $\mathrm{MgO}$ & $\mathrm{Na}_{2} \mathrm{O}$ & $\mathrm{K}_{2} \mathrm{O}$ & $\begin{array}{c}\text { Specific } \\
\text { Surface Area } \\
\left(\mathrm{m}^{2} / \mathrm{kg}\right)\end{array}$ & $\begin{array}{c}\text { Specific } \\
\mathrm{Gravity} \\
\left(\mathrm{kg} / \mathrm{m}^{3}\right)\end{array}$ & $\begin{array}{c}\text { LOI } \\
\text { Ignition, on }\end{array}$ \\
\hline 61.89 & 18.73 & 5.88 & 3.37 & 2.08 & 3.24 & 0.31 & 0.15 & 360 & 3170 & 3.03 \\
\hline
\end{tabular}

Table 2. Chemical composition of the FA (wt.\%).

\begin{tabular}{ccccccccccc}
\hline $\mathrm{SiO}_{2}$ & $\mathrm{Al}_{2} \mathbf{O}_{3}$ & $\mathrm{Fe}_{2} \mathbf{O}_{3}$ & $\mathrm{CaO}$ & $\mathbf{K}_{\mathbf{2}} \mathbf{O}$ & $\mathbf{N a}_{2} \mathbf{O}$ & $\mathbf{M g O}$ & $\mathbf{S O}_{3}$ & $\mathbf{Z n O}$ & $\mathrm{TiO}_{2}$ & $\mathbf{P}_{2} \mathrm{O}_{5}$ \\
\hline 49.72 & 31.09 & 6.04 & 3.81 & 0.41 & 0.17 & 1.53 & 1.49 & 0.08 & 2.58 & 0.42 \\
\hline
\end{tabular}




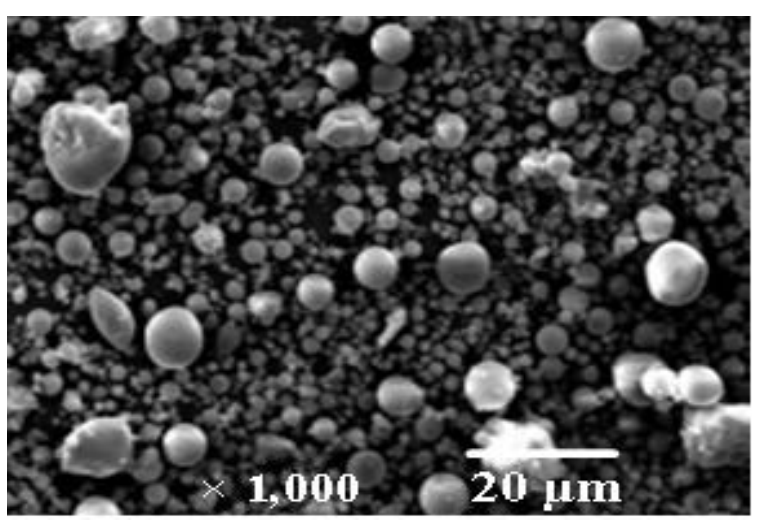

Figure 1. Scanning electron micrograph of fly ash (FA).

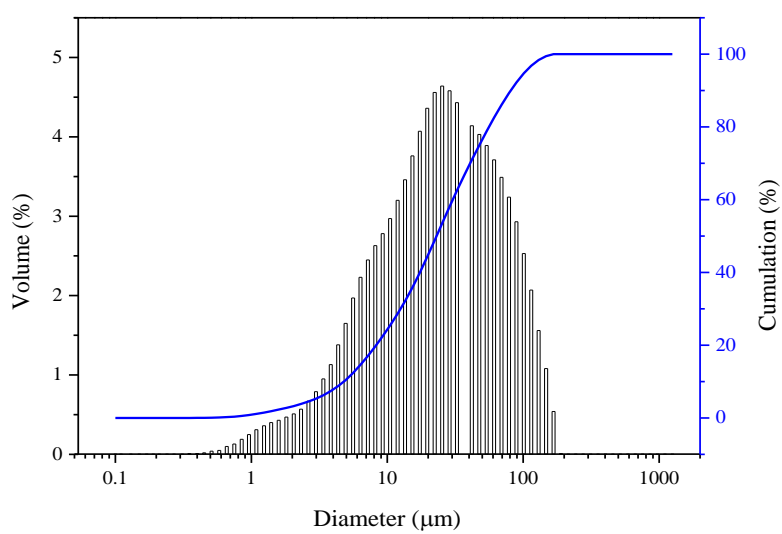

Figure 2. Particle size distribution of FA.

\subsubsection{Aggregate}

The fine aggregate used was river sand (RS) with a fineness modulus of 2.60 (medium sand); it has water absorption of $1.15 \%$ and specific gravity of 2.45 . The coarse aggregates used were NCA (broken granite gravel) and RCA (laboratory waste concrete block) and with continuous grading. The maximum size of the coarse aggregates was $25 \mathrm{~mm}$. Table 3 lists the properties of RCA and NCA. The properties of fine and coarse aggregates complied with the Chinese standards GB/T 14684-2011 [26] and GB/T14685-2011 [27], respectively.

Table 3. Properties of coarse aggregate.

\begin{tabular}{ccccc}
\hline Type & $\begin{array}{c}\text { Water Absorption } \\
(\mathbf{\%})\end{array}$ & $\begin{array}{c}\text { Crushing Value Index } \\
(\mathbf{\%})\end{array}$ & $\begin{array}{c}\text { Apparent Density } \\
\left(\mathbf{k g} / \mathbf{m}^{\mathbf{3}}\right)\end{array}$ & $\begin{array}{c}\text { Bulk Density } \\
\left(\mathbf{k g} / \mathbf{m}^{\mathbf{3}} \mathbf{)}\right.\end{array}$ \\
\hline NCA & 1.06 & 9.80 & 2561 & 1380 \\
RCA & 5.48 & 15.7 & 2509 & 1253 \\
\hline
\end{tabular}

\subsubsection{Polypropylene Fiber}

PP with a length of $12 \mathrm{~mm}$ was used to improve the damping property of RAC. Table 4 shows the primary physical and mechanical properties of PP.

Table 4. Main physical and mechanical properties of polypropylene fiber (PP).

\begin{tabular}{ccccc}
\hline $\begin{array}{c}\text { Diameter } \\
(\boldsymbol{\mu m})\end{array}$ & $\begin{array}{c}\text { Density } \\
\left(\mathbf{k g} / \mathbf{m}^{\mathbf{3}}\right)\end{array}$ & $\begin{array}{c}\text { Tensile Strength } \\
\mathbf{( M P a})\end{array}$ & $\begin{array}{c}\text { Elastic Modulus } \\
(\mathbf{G P a})\end{array}$ & $\begin{array}{c}\text { Elongation } \\
(\mathbf{\%})\end{array}$ \\
\hline $15-40$ & 920 & 450 & 3.81 & 20 \\
\hline
\end{tabular}




\subsubsection{Admixture}

Polycarboxylate superplasticizer (SP) with a water reduction ratio of $30 \%$ and solid content of $35 \%$ was used in this study. An AGA with a specific density of $1.02 \%$ was used to enhance the damping property of the concrete.

\subsection{Mixture Preparation}

Nine different mixtures of RAC modified with AGA (wt.\%) and PP (V\%) were prepared. Tables 5 and 6 show the mixture proportions of reference concrete and RAC, respectively. The specimens were formed based on the content. For e.g., in 50RAC-A1, 50 indicates that the replacement percentage of RCA is $50 \%$ (wt.), and A1 indicates that the content of AGA is $0.072 \mathrm{~kg} / \mathrm{m}^{3}$. The mixing water consisted of two parts: water consumption of ordinary concrete mix design and additional water. It should be noted that the additional water did not change the effective water-to-binder ratio of the mixture.

Table 5. Mixture proportion of reference concrete $\left(\mathrm{kg} / \mathrm{m}^{3}\right)$.

\begin{tabular}{cccccccccc}
\hline $\begin{array}{c}\text { Concrete } \\
\text { ID }\end{array}$ & Cement & FA & RS & NCA & RCA & $\begin{array}{c}\text { Water } \\
\text { (Additional Water) }\end{array}$ & PP & SP & AGA \\
\hline $\mathrm{R}$ & 280 & 70 & 640 & 1040 & 0 & $175(0)$ & 0 & 3.5 & 0 \\
\hline
\end{tabular}

Table 6. Mixture proportions of reference concrete and recycled aggregate concrete (RAC).

\begin{tabular}{ccccccc}
\hline Concrete ID & $\begin{array}{c}\text { NCA } \\
\mathbf{( \% )}\end{array}$ & $\begin{array}{c}\text { RCA } \\
\mathbf{( \% )}\end{array}$ & $\begin{array}{c}\text { PP } \\
\mathbf{( \% )}\end{array}$ & $\begin{array}{c}\text { AGA } \\
\mathbf{( \% )}\end{array}$ & $\begin{array}{c}\text { SP(\%) } \\
\text { R }\end{array} 1$ Water (Additional Water) \\
$\mathbf{( k g / \mathbf { m } ^ { 3 } )}$
\end{tabular}

\subsection{Test Methods}

For testing the compressive strength, Young's modulus, and splitting tensile strength, $150 \mathrm{~mm} \times$ $150 \mathrm{~mm} \times 150 \mathrm{~mm}$ cubic molds, $100 \mathrm{~mm} \times 100 \mathrm{~mm} \times 400 \mathrm{~mm}$ prism, and $150 \mathrm{~mm} \times 150 \mathrm{~mm} \times 300 \mathrm{~mm}$ prism cubic molds were used, respectively, according to GB/T 50081-2002 [28]. The test samples were demolded $24 \mathrm{~h}$ after the initial casting and were put in a standard curing room $\left(20 \pm 1^{\circ} \mathrm{C}, \geq 95 \% \mathrm{RH}\right)$ until the testing day.

The dynamic modulus of elasticity of the concrete was determined by the resonant frequent method in accordance with GB/T 50082-2009 [29]. It was calculated according to the following equation:

$$
E_{d}=13.244 \times 10^{-4} \times \frac{W L^{3} f^{2}}{\alpha^{4}}
$$

where $E_{d}, \mathrm{~W}, \mathrm{~L}, f$, and $\alpha$ represent the dynamic modulus of elasticity of RAC (MPa), weight of sample $(\mathrm{kg})$, length of test sample $(\mathrm{mm})$, transverse frequency of the specimen $(\mathrm{Hz})$, and the side length of square cross-section sample $(\mathrm{mm})$, respectively.

The damping ratio of concrete was evaluated by the vibration of a free-free beam. A pulse hardware/software vibration analysis system (Brüel and Kjær) was utilized to record the acceleration response signals as time magnitude and hammer force, as shown in Figure 3. The ME'Scope modal analysis program was used to record the data and convert it to frequency-magnitude $\left(\mathrm{m}^{2} / \mathrm{s}\right)$ graphs, as 
shown in Figure 4, and then the resonant frequency $\left(\mathrm{f}_{0}\right)$ was obtained [7]. The half-power bandwidth method was applied to measure the damping ratio of the concrete [30]. All specimens with a dimension of $100 \mathrm{~mm} \times 100 \mathrm{~mm} \times 400 \mathrm{~mm}$ underwent damping ratio test after 28 days of curing. The damping ratio of concrete can be expressed as follows:

$$
\xi=\frac{\left(f_{1}-f_{2}\right)}{2 f_{0}}
$$

where $\xi, \mathrm{f}_{1}$, and $\mathrm{f}_{2}$ represent the damping ratio of concrete $(\%)$, frequency corresponding to an amplitude of $\mathrm{f}_{0} / \sqrt{ } 2(\mathrm{~Hz})$, and the resonant frequency of concrete $(\mathrm{Hz})$, respectively.

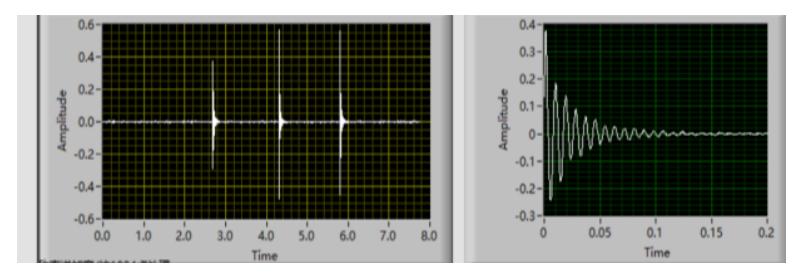

Figure 3. Time-magnitude signal as the acceleration response signal.

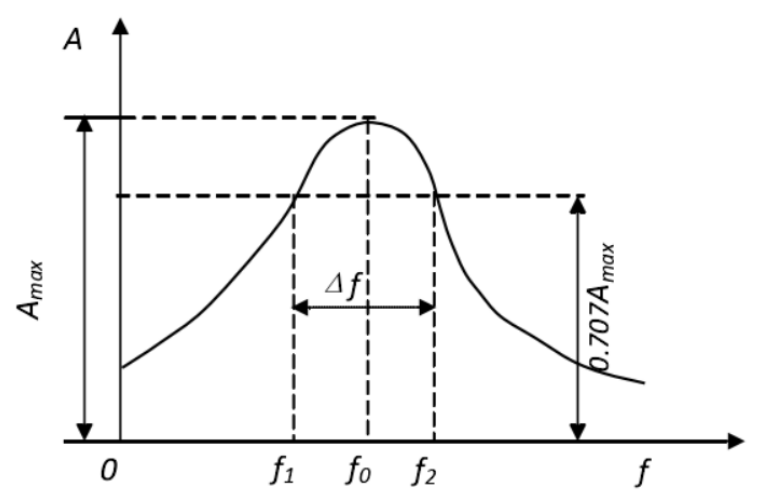

Figure 4. Estimation of the damping ratio of concrete using the half-power bandwidth method [29].

\section{Results and Discussion}

\subsection{Static Properties}

\subsubsection{Compressive Strength}

Figure 5a shows the compressive strength of the reference concrete and RAC modified with PP and AGA. The compressive strength of the samples decreased by 3.37\% (50RAC) and 40.04\% (100 RAC) as compared to that of the reference concrete after 28 days of curing. It is evident that RCA has a marginal effect on the compressive strength of RAC with replacement percentage of $50 \%$, while the RAC with replacement percentage of $100 \%$ is significantly affected. Similar results were reported by Liang et al. [4]. This behavior can be attributed to the higher absorption and crushing value of RCA, as shown in Table 3.

Further, a large number of micro-cracks and voids exist in the old cement mortar and ITZs of RAC, as seen in Figure 5a. The accumulation of water film at the ITZ near the surface of the aggregate and the growth of a large amount of hydration products, calcium hydroxide and ettringite $(\mathrm{CH}$ and $\mathrm{AFt}$ ) on the surface of ITZ cause a porous ITZ in the RAC [4]. Furthermore, RAC has weak ITZs due to the poor adherence between the old aggregate and the new cement mortar, which causes the specimen (100RAC) to exhibit the lowest compressive strength [11,12]. Moreover, the weak properties of RCA (Table 3) and the characteristics of ITZs positively affected the energy dissipation of RAC. This is discussed in Section 3.2.2. 

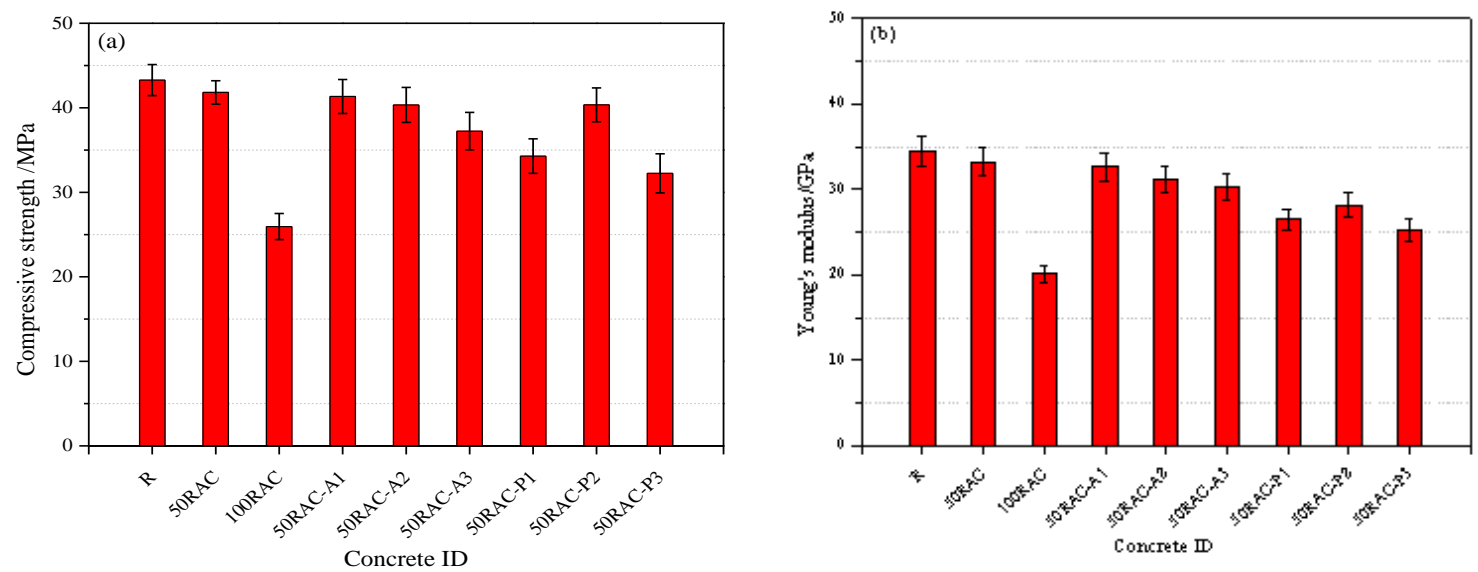

Figure 5. Static properties of concrete after 28 days of curing: (a) compressive strength and (b) Young's modulus.

The compressive strength of RAC slightly decreased by 1.15\% (50RAC-A1) and 3.54\% (50RAC-A2) when the AGA content was below $0.02 \%$, but was sharply reduced to $10.95 \%$ (50RAC-A3) for the mixture containing $0.03 \%$ AGA as compared to that of the 50RAC sample after 28 days of curing. This could be attributed to the increment of porosity due to the introduction of AGA in concrete.

The compressive strength of the RAC decreased by 18.03\% (50RAC-P1), 3.15\% (50RAC-P2), and $22.89 \%$ (50RAC-P3) than that of 50RAC after 28 days of curing. The PP-reinforced RAC consisted of six phases: original aggregate, natural aggregate, cement mortar (new cement mortar and old cement mortar), new ITZ (between the NCA and new cement mortar), old ITZ (between the NCA and old cement mortar), and ITZ between the fiber and cement mortar [4]. A large number of micro-cracks were observed in the ITZ between the fibers and cement mortar, as shown in Figure 6. In addition, the thickness of the fiber-cement mortar ITZ was larger than that of the old ITZ in RAC, resulting in a significant gap between the micro-hardness of ITZs $[1,10]$. This hindered the mechanical performance of RAC.
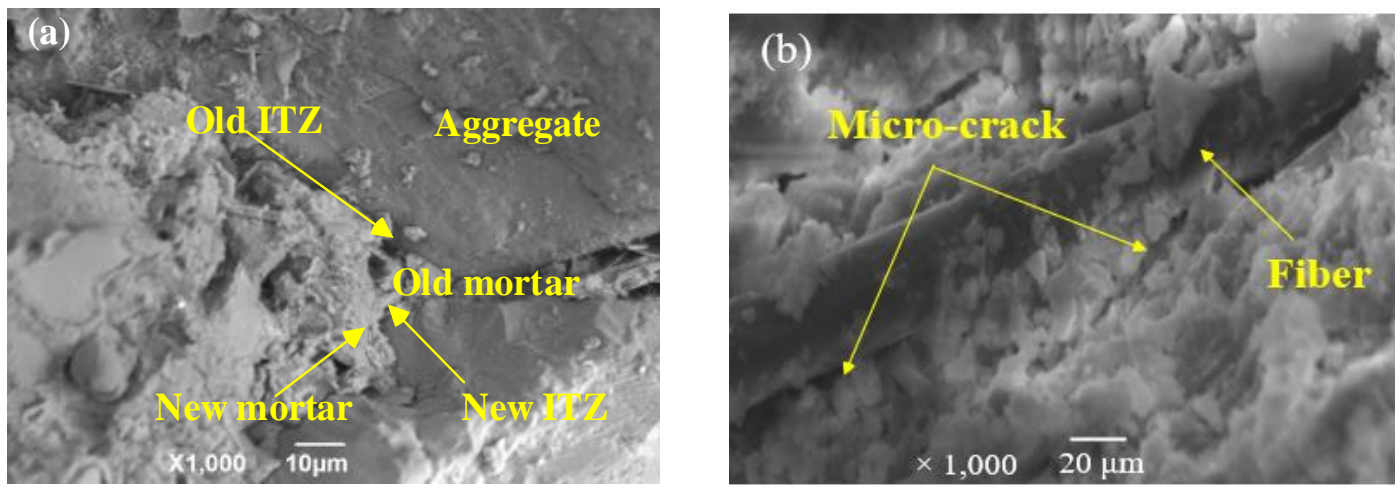

Figure 6. Interface transition zones (ITZs) in RAC: (a) ITZ between aggregate and cement mortar and (b) ITZ between fiber and cement mortar.

\subsubsection{Young's Modulus}

Figure 5b shows the Young's modulus of the reference concrete and the RAC modified with PP and AGA. It is evident that the effect of RCA on the reduction of Young's modulus is stronger than that of the addition of AGA and PP.

The Young's modulus of the RAC decreases by $3.77 \%$ and $41.74 \%$ for RCA with replacement percentage of $50 \%$ and $100 \%$, respectively, as compared to that of the reference concrete. Furthermore, the Young's modulus of the RAC decreased with increasing AGA content. A slightly decreasing trend 
is observed when the AGA content is less than $0.02 \%$. However, when the AGA content is higher than $0.02 \%$, the Young's modulus of the specimens (50RAC-A3) exhibit a significant reduction. Figure $5 \mathrm{~b}$ shows that the Young's modulus of the mixtures 50RAC-P1, 50RAC-P2, and 50RAC-P3 containing $0.09 \%, 0.10 \%$, and $0.11 \%$ PP is reduced by $15.52 \%, 10.15 \%$, and $25.07 \%$, respectively, as compared to that of 50RAC.

Previous studies have indicated that the properties of aggregates significantly affect the Young's modulus of concrete [3,4]. The reduction in Young's modulus is primarily attributed to the low strength and elastic modulus of RCA. Therefore, the Young's modulus of concrete can be significantly controlled by the properties of RCA.

\subsubsection{Splitting Tensile Strength}

Figure 7 shows the splitting tensile strength of the reference concrete and RAC modified with PP and AGA. The effect of RCA on the splitting tensile strength of RCA is similar to that on the compressive strength. The splitting tensile strength of the concrete decreases by $3.97 \%$ (50RAC) and $17.78 \%$ (100RAC) as compared to that of the natural aggregate concrete (NAC) after 28 days of curing.
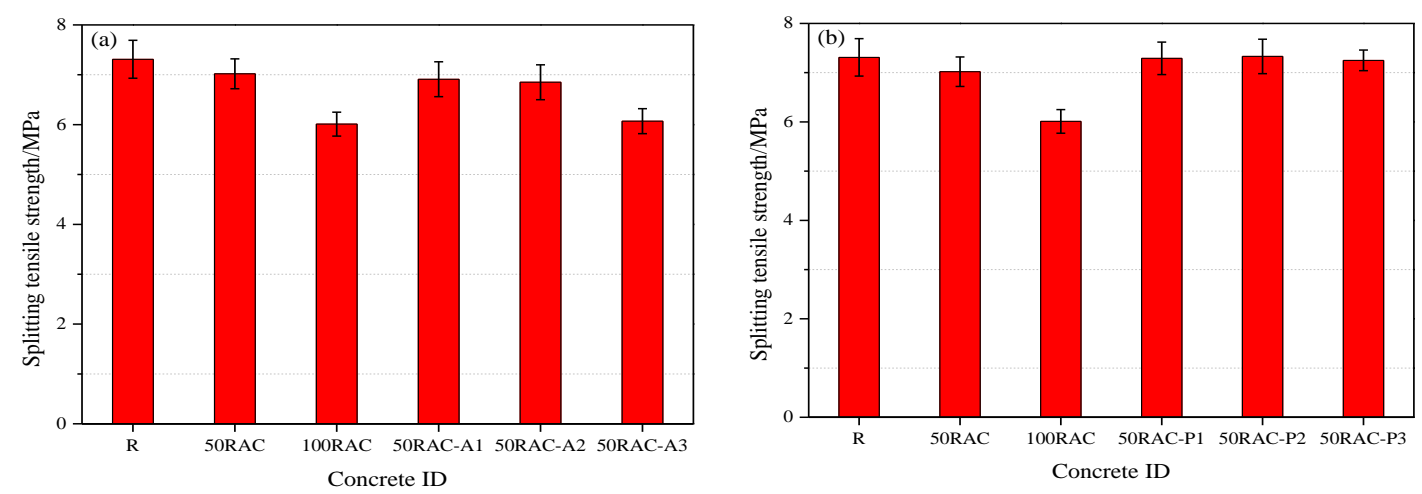

Figure 7. Splitting tensile strength of concrete after 28 days of curing: (a) reference concrete and RAC modified with AGA and (b) reference concrete and RAC modified with PP.

Furthermore, the splitting tensile strength of concrete decreases by $1.57 \%$ (50RAC-A1), $2.42 \%$ (50RAC-A2), and $13.53 \%$ (50RAC-A3) as compared to that of the 50RAC samples. Therefore, a similar conclusion as that from the compressive strength test can be drawn, i.e., a higher dose of AGA adversely affects the splitting tensile property of the RACs regardless of the replacement ratio of the RCA. While a slight increment was found for the specimen containing PP, the splitting tensile strength of concrete increased by $3.85 \%$ (50RAC-P1), $4.42 \%$ (50RAC-P2), and 3.27\% (50RAC-P3). Similar conclusions have been reported by earlier studies $[23,31]$.

\subsection{Dynamic Behavior}

The dynamic behavior, i.e., the dynamic modulus of elasticity and damping ratio of the reference concrete and the RAC modified with AGA and PP, is shown in Figure 8.

\subsubsection{Dynamic Modulus of Elasticity}

It is evident from Figure $8 \mathrm{a}$ that the dynamic modulus of elasticity of the RAC decreases by $9.38 \%$ (50RAC) and 56.07\% (100RAC) as compared to the reference concrete.

The dynamic modulus of elasticity of the samples 50RAC-A1, 50RAC-A2, and 50RAC-A3 decreases by $1.60 \%, 4.34 \%$, and $13.65 \%$, respectively, as compared to that of 50RAC specimen. It is clear seen that the dynamic modulus of elasticity decreases with the increase in the replacement percentage of RCA and the AGA content. The dynamic modulus of elasticity of the samples 50RAC-P1, 50RAC-P2, and 50RAC-P3 decreases by $22.51 \%, 4.62 \%$, and $29.64 \%$, respectively, indicating that the addition of PP can 
significantly reduce the dynamic modulus of elasticity of RAC with the exception for concrete with $0.50 \%$ PP.
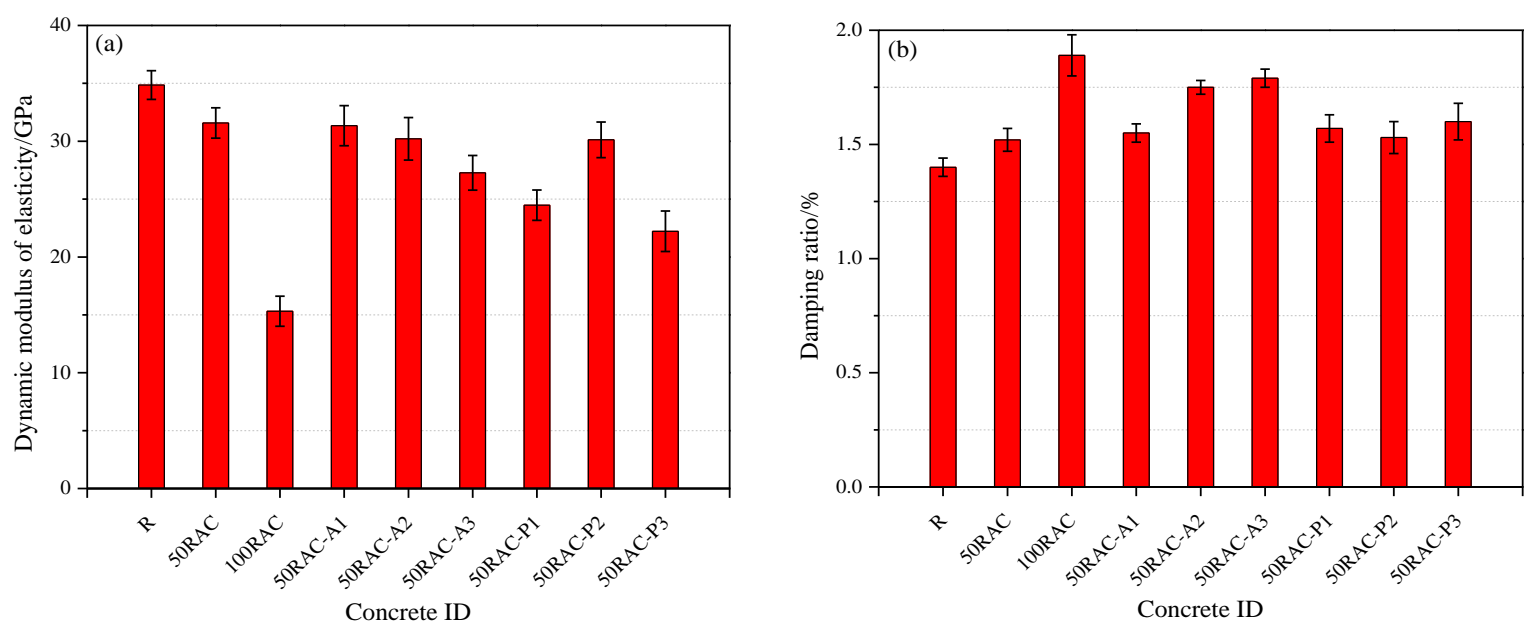

Figure 8. Dynamic behavior of the reference concrete and RAC modified with AGA and PP: (a) dynamic modulus of elasticity and (b) damping ratio.

\subsubsection{Damping Ratio}

The damping ratio of concrete exhibits a sharply increasing trend with the increase in the replacement percentage of RCA, as seen in Figure 8b. The damping ratio of the samples 50RAC and 100RAC is enhanced by $7.86 \%$ and $35.00 \%$, respectively, as compared to that of the reference concrete after 28 days of curing. Similar results have been reported by Liang et al. [4], Lin et al. [10], and Li et al. [11]. The elastic modulus of different phases significantly varies in RAC. For e.g., the elastic modulus of the aggregate is much larger than that of the cement mortar and ITZs (old ITZ and new ITZ). Further, there is a considerable difference between the elastic modulus of various phases [4].

Previous reports have indicated that the indentation modulus of new cement mortar is 1.18 times that of new ITZ, while the indentation modulus of the old cement mortar is approximately 1.33 times higher than that of the old ITZ in the RAC [4], which is confirmed in Figure 9. Hence, the addition of RCA can increase the proportion of the old cement mortar and ITZs of RAC, which enhances the inhomogeneity of RAC and contribute to the relative deformation between different phases in RAC $[11,30,31]$.

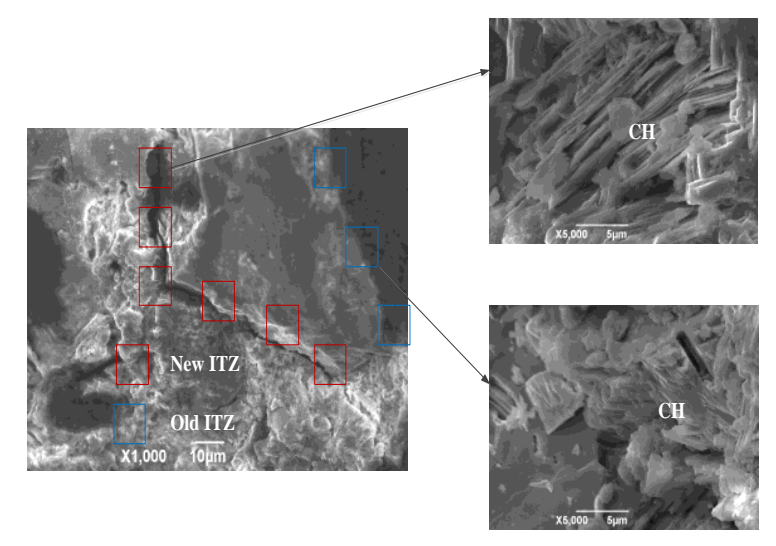

Figure 9. Images showing ITZs in RAC.

The damping ratio of RAC increases with the increase in the AGA content. This increasing trend is more obvious when the AGA content is above $0.02 \%$. The central function of the AGA is to introduce several air bubbles and pores into the concrete, which plays a vital role in flexible cushioning bag 
when the structure is subjected to external vibration, as shown in Figure 10. The bubbles and voids in the RAC improve the damping capacity of RAC. As the AGA content increases, the introduction of bubbles and voids reaches a certain amount, and the damping property of the RAC attains its optimal value. Further increase in the amount of AGA does not have a significant effect on damping ratio of RAC. On the contrary, it significantly reduces the mechanical properties of the RAC, as discussed in Section 3.1. Therefore, for the same replacement percentage of RAC, the optimal content of AGA to simultaneously attain improved mechanical properties and dynamic characteristics is $0.02 \%$.

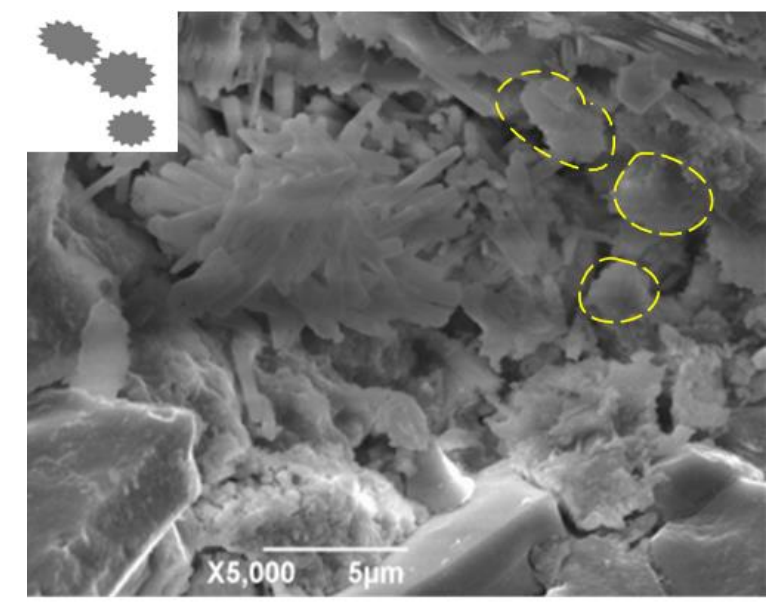

Figure 10. Bubbles and voids in RAC.

The damping ratio of the samples 50RAC-P1, 50RAC-P2, and 50RAC-P3 increases by $3.18 \%$, $0.66 \%$, and $5.26 \%$, respectively, as compared to that of the 50RAC specimen after 28 days of curing. This can be attributed to the significant gap between the micro-hardness of ITZs (new ITZ, old ITZ, and fiber-cement mortar ITZ), which increases the energy dissipation of RAC due to the sliding between the ITZs [18], as shown in Figure 9. The proportion of ITZs increases with the content of PP, which leads to higher energy dissipation of RAC. All these effects are conducive to improve the damping ratio of RAC. On the contrary, the bubbles and voids in the RAC adversely affect the mechanical properties of RAC, as discussed in Section 3.1. Therefore, it can be concluded that the addition of AGA is more effective than that of PP for increasing the damping ratio of RAC.

\section{Conclusions}

We prepared RAC containing PP and AGA and evaluated their damping properties and mechanical performance at various AGA and PP contents. The important results of this study are summarized as follows:

1. The RCA had a marginal effect on the mechanical properties of RAC with a replacement aggregate percentage of $50 \%$ (reduced by approximately $5 \%$ ). However, the mechanical properties of the RAC with $100 \%$ replacement aggregate were significantly affected (approximately decreased by $40 \%$ ) than those of the reference concrete.

2. The addition of both AGA and PP adversely affected the mechanical properties of the concrete, and the effect of PP addition on the reduction of the mechanical properties of RAC was stronger than that of AGA addition. The compressive strength and Young's modulus reduced slightly when the AGA content was below $0.02 \%$.

3. The addition of both AGA and PP favorably affected the damping property of the concrete, and the addition of AGA was more effective than that of $\mathrm{PP}$ in increasing the damping ratio of the RAC. Furthermore, the AGA and PP contents to achieve the optimum dynamic property of the concrete with the least reduction in the mechanical performance were determined to be $0.02 \%$ and $0.10 \%$, respectively. 
Author Contributions: Conceptualization, Y.L.; Data curation, Y.L.; Formal analysis, X.P.; Funding acquisition, X.P.; Investigation, W.L.; Project administration, X.P.; Software, C.Z.; Supervision, W.L.; Validation, Y.L.; Visualization, W.L.; Writing—original draft, C.Z.; Writing—review \& editing, C.Z. All authors have read and agree to the published version of the manuscript.

Funding: This research was funded by National Natural Science Foundation of China, grant number 51808424.

Conflicts of Interest: The authors declare no conflict of interest.

\section{References}

1. Lu, D.; Tang, Z.; Zhang, L.; Zhou, J.; Gong, Y.; Tian, Y.; Zhong, J. Effects of combined usage of supplementary cementitious materials on the thermal properties and microstructure of high-performance concrete at high temperatures. Materials 2020, 13, 1833. [CrossRef] [PubMed]

2. Saavedra, W.G.V.; de Gutiérrez, R.M. Performance of geopolymer concrete composed of fly ash after exposure to elevated temperatures. Constr. Build. Mater. 2017, 154, 229-235. [CrossRef]

3. Wang, Z.; Li, L.; Zhang, Y.; Wang, W. Bond-slip model considering freeze-thaw damage effect of concrete and its application. Eng. Struct. 2019, 201, 109831. [CrossRef]

4. Liang, C.; Liu, T.; Xiao, J.; Zou, D.; Yang, Q. The damping property of recycled aggregate concrete. Constr. Build. Mater. 2016, 102, 834-842. [CrossRef]

5. Long, G.; Yang, J.; Xie, Y. The mechanical characteristics of steam-cured high strength concrete incorporating with lightweight aggregate. Constr. Build. Mater. 2017, 136, 456-464. [CrossRef]

6. Zhang, Y.; Bicici, E.; Sezen, H.; Zheng, S. Reinforcement slip model considering corrosion effects. Constr. Build. Mater. 2020, 235, 117348. [CrossRef]

7. Tian, Y.; Shi, S.; Jia, K.; Hu, S. Mechanical and dynamic properties of high strength concrete modified with lightweight aggregates presaturated polymer emulsion. Constr. Build. Mater. 2015, 93, 1151-1156. [CrossRef]

8. Yoon, J.Y.; Kim, J.H. Mechanical properties of preplaced lightweight aggregates concrete. Constr. Build. Mater. 2019, 216, 440-449. [CrossRef]

9. Li, W.; Lang, L.; Wang, D.; Wu, Y.; Li, F. Investigation on the dynamic shear modulus and damping ratio of steel slag sand mixtures. Constr. Build. Mater. 2018, 162, 170-180. [CrossRef]

10. Lin, J.; Hong, J.; Xiao, Y. Dynamic characteristics of $100 \%$ cold recycled asphalt mixture using asphalt emulsion and cement. J. Clean. Prod. 2017, 156, 337-344. [CrossRef]

11. Li, T.; Xiao, J.; Sui, T.; Liang, C.; Li, L. Effect of recycled coarse aggregate to damping variation of concrete. Constr. Build. Mater. 2018, 178, 445-452. [CrossRef]

12. Wang, C.; Xiao, J.; Wang, C.; Zhang, C. Nonlinear damping and nonlinear responses of recycled aggregate concrete frames under earthquake loading. Eng. Struct. 2019, 201, 109575. [CrossRef]

13. Giner, V.T.; Ivorra, S.; Baeza, F.J.; Zornoza, E.; Ferrer, B. Silica fume admixture effect on the dynamic properties of concrete. Constr. Build. Mater. 2011, 25, 3272-3277. [CrossRef]

14. Tang, X.; Yan, X. Acoustic energy absorption properties of fibrous materials: A review. Compos. Appl. Sci. Manuf. 2017, 101, 360-380. [CrossRef]

15. Cortés, F.; Castillo, G. Comparison between the dynamical properties of polymer concrete and grey cast iron for machine tool applications. Mater. Des. 2007, 28, 1461-1466. [CrossRef]

16. Scalerandi, M.; Bentahar, M.; Mechri, C. Conditioning and elastic nonlinearity in concrete: Separation of damping and phase contributions. Constr. Build. Mater. 2018, 161, 208-220. [CrossRef]

17. Liew, K.M.; Kai, M.F.; Zhang, L.W. Mechanical and damping properties of CNT-reinforced cementitious composites. Compos. Struct. 2017, 160, 81-88. [CrossRef]

18. Bentz, D.P. Influence of internal curing using lightweight aggregates on interfacial transition zone percolation and chloride ingress in cement mortars. Cem. Concr. Compos. 2009, 31, 285-289. [CrossRef]

19. Jeon, E.B.; Ahn, S.K.; Lee, I.G.; Koh, H.I.; Park, J.; Kim, H.S. Investigation of mechanical/dynamic properties of carbon fiber reinforced polymer concrete for low noise railway slab. Compos. Struct. 2015, 134, 27-35. [CrossRef]

20. Wang, Z.; Li, L.; Zhang, Y.; Zheng, S. Reinforcement model considering slip effect. Eng. Struct. 2019, 198, 109493. [CrossRef] 
21. Al-Subaihawi, S.; Kolay, C.; Marullo, T.; Ricles, J.M.; Quiel, S.E. Assessment of wind-Induced vibration mitigation in a tall building with damped outriggers using real-time hybrid simulations. Eng. Struct. 2020, 205, 110044. [CrossRef]

22. Fracois, D.L.; Horacio, C. Concrete Recycling: Research and Practice; CRC Press: Boca Raton, FL, USA, 2019; ISBN 9781138724723.

23. Liu, W.H.; Li, H.; Zhu, H.M.; Xu, P.J. The Interfacial Adhesion Performance and Mechanism of a Modified Asphalt-Steel Slag Aggregate. Materials 2020, 13, 1180. [CrossRef] [PubMed]

24. China Architecture and Building. Common Portland Cement (GB175-2007); China Architecture and Building Press: Beijing, China, 2007. (In Chinese)

25. China Architecture and Building. Fly Ash Used for Cement and Concrete (GB/T1596-2005); China Architecture and Building Press: Beijing, China, 2005. (In Chinese)

26. China Architecture and Building. Sand for Construction (GB/T 14684-2011); China Architecture and Building Press: Beijing, China, 2011. (In Chinese)

27. China Architecture and Building. Pebble and Crushed Stone for Construction (GB/T14685-2011); China Architecture and Building Press: Beijing, China, 2011. (In Chinese)

28. China Architecture and Building. Standard for Test Method of Mechanical Properties on Ordinary Concrete (GB/T 50081-2002); China Architecture and Building Press: Beijing, China, 2002. (In Chinese)

29. China Architecture and Building. Standard for Test Method of Long-term Performance and Durability of Ordinary Concrete (GB/T 50082-2009); China Architecture and Building Press: Beijing, China, 2009. (In Chinese)

30. Papagiannopoulos, G.A.; Hatzigeorgiou, G.D. On the Use of the Half-Power Bandwidth Method to Estimate Damping in Building Structures. Soil Dyn. Earthq. Eng. 2011, 31, 1075-1079. [CrossRef]

31. Xuan, D.G.; Zhan, B.J.; Poon, C.S. Durability of Recycled Aggregate Concrete Prepared with Carbonated Recycled Concrete Aggregates. Cem. Concr. Compos. 2017, 84, 214-221. [CrossRef]

(C) 2020 by the authors. Licensee MDPI, Basel, Switzerland. This article is an open access article distributed under the terms and conditions of the Creative Commons Attribution (CC BY) license (http://creativecommons.org/licenses/by/4.0/). 